\title{
Retrospective Impact Analysis and Cost-Effectiveness of the Pneumococcal Conjugate Vaccine Infant Program in Australia
}

\author{
Johnna Perdrizet (D) - Yuen S. Lai · Scott Williams · Valda A. Struwig • \\ Matt Wasserman
}

Received: November 16, 2020 / Accepted: January 27, 2021 / Published online: February 11, 2021

(c) The Author(s) 2021

\section{ABSTRACT}

Australia introduced the 7-valent pneumococcal conjugate vaccine $(7 \mathrm{vPCV})$ on the universal infant National Immunisation Program (NIP) in 2005 and replaced it with the 13-valent pneumococcal conjugate vaccine (13vPCV) in 2011, both under a $3+0$ schedule. The objective of this analysis was to quantify the clinical and economic impact of the universal infant PCV program in Australia from its introduction. A decision-analytic model was developed to estimate the historical impact of pneumococcal conjugate vaccine (PCV) programs in Australia from a direct health care perspective. Historical incidence of invasive pneumococcal disease (IPD), pneumonia, and otitis media (OM) were obtained from available Australian epidemiologic databases supplemented with published data. Costs were from Medicare Benefits Schedule in 2018 Australian dollars and utility weights from published sources. Historical observed changes in disease for the universal

J. Perdrizet $(\square) \cdot$ M. Wasserman

Health Economics and Outcomes Research, Pfizer

Inc., New York, NY, USA

e-mail: johnna.perdrizet@pfizer.com

Y. S. Lai · S. Williams

Medical and Scientific Affairs, Pfizer Australia,

Sydney, Australia

V. A. Struwig

Market Access, Pfizer Australia, Sydney, Australia
PCV NIP era (2005-2017) were compared against a "no-vaccine" scenario. The expected incidence for the no-vaccine scenario in years 2005-2017 was calculated using pre-universal PCV NIP era (2001-2004) data. Averted cases, deaths, incremental costs, and quality-adjusted life years (QALYs) were obtained by subtracting the vaccine scenario totals from the no-vaccine scenario totals. From the inclusion in the universal infant NIP, 7vPCV and $13 \mathrm{vPCV}$ are estimated to have prevented $1,770,024$ cases of pneumococcal disease $(\mathrm{IPD}=16,392 ; \mathrm{OM}=$ $1,575,491$; pneumonia $=102,059)$ and 1195 associated deaths. Over this period, there was a total 24,335 QALYs gained. Costs for the universal infant NIP were offset by $\$ 733$ million direct costs saved, resulting in an incremental cost-effectiveness ratio of $\$ 3347$ per QALY gained. PCVs have provided substantial public health and economic value from sustained use in Australia. Results are conservative, since long-term pneumococcal disease consequences and broader socioeconomic benefits were not considered. Maintaining 13vPCV on the Australian infant NIP under the newly implemented $2+1$ schedule will likely provide more return on investment and sustained reductions in pneumococcal disease.

Keywords: Cost-effectiveness analysis; Economic evaluation; Otitis media; Pneumococcal 
conjugate vaccine; Pneumococcal disease; Pneumonia; Vaccines

\section{Key Summary Points}

\section{Why carry out this study?}

In Australia, publicly funded vaccination programs are periodically reevaluated to ensure scarce resources are used in a costeffective manner.

The 7-valent pneumococcal conjugate vaccine $(7 \mathrm{vPCV})$ and the 13 -valent (13vPCV) have been on the infant National Immunisation Program since 2005 and have provided benefit through direct and indirect protection, yet the public health and economic impact have not been retrospectively quantified.

What was learned from the study?

PCVs have demonstrated substantial return on investment and have proven their importance for a healthy population, given that for every two infants vaccinated one case of pneumococcal disease has been prevented in Australia.

Evidence supports the continuation of $13 \mathrm{vPCV}$ considering this program has prevented substantial disease burden and saved disease-related costs in all ages.

\section{DIGITAL FEATURES}

This article is published with digital features, including a summary slide, to facilitate understanding of the article. To view digital features for this article go to https://doi.org/10.6084/ m9.figshare.13626263.

\section{INTRODUCTION}

Pneumococcal disease is caused by the bacterium Streptococcus pneumoniae. It can cause severe invasive pneumococcal disease (IPD), including meningitis, pneumonia and bacteremia, and non-invasive disease, including otitis media $(\mathrm{OM})$ and non-invasive pneumonia [1]. Although IPD is more severe and has a greater chance of leading to mortality, pneumonia and OM represent a significant portion of the burden of disease and associated medical costs [2-4].

A 7-valent pneumococcal conjugate vaccine (7vPCV) was registered by the Therapeutic Goods Administration in 2000. In mid-2001, it was introduced onto the National Immunisation Program (NIP) for children at highest risk of IPD including Aboriginal and Torres Strait Islander infants $(3+0$ schedule at 2,4 and 6 months of age), children with specified underlying medical conditions that predispose them to IPD $(3+1$ schedule at $2,4,6$, and 12 months of age), and non-Indigenous children in Central Australia ( $3+0$ schedule at 2, 4 and 6 months of age) and as a catch-up program for non-Indigenous children (children in Central Australia $<2$ years of age, Aboriginal and Torres Strait Islander children in Central Australia $<5$ years of age, and Aboriginal and Torres Strait Islander children in northern $\mathrm{NT}<2$ years of age). The $7 \mathrm{vPCV}$ became a part of the NIP for all infants $(3+0$ schedule at 2,4 and 6 months of age) in 2005 with a catchup program for children $<2$ years of age. After the introduction of $7 \mathrm{vPCV}$ in many countries, IPD incidence due to the seven serotypes covered by $7 \mathrm{vPCV}(4,6 \mathrm{~B}, 9 \mathrm{~V}, 14,18 \mathrm{C}, 19 \mathrm{~F}$ and $23 \mathrm{~F})$ was largely eradicated [5-8], but non-7vPCV serotypes began to emerge with a statistically significant increase for serotype 19A [5]. Subsequently, a 13-valent pneumococcal conjugate vaccine $(13 \mathrm{vPCV})$, covering the $7 \mathrm{vPCV}$ serotypes plus $1,3,5,6 \mathrm{~A}$ and $7 \mathrm{~F}$ and $19 \mathrm{~A}$ was registered in Australia and replaced $7 \mathrm{vPCV}$ on the NIP for all infants from July 2011. At the time of introduction of $7 \mathrm{vPCV}$ on the NIP for all infants (2005), the 23-valent pneumococcal polysaccharide vaccine (23vPPV) also became available on the NIP for all adults aged $\geq 65$ years.

Since inclusion on the NIP, PCVs have substantially reduced the clinical burden of pneumococcal disease, which is associated with a 
reduction in health care resources. However, as in other countries internationally, public health budgets remain a significant issue. Consequently, publicly funded vaccination programs are periodically reevaluated to ensure scarce resources are used in a cost-effective manner and so that programs in place deliver on what is expected. This is particularly true if the burden of disease is judged under control as a result of a successful vaccination program. When reviewing existing programs, it is critical that policy makers consider the total value of a vaccination program to the healthcare system and society rather than just its cost. Previous studies have considered the impact of the $7 \mathrm{vPCV}$ pediatric NIP in Australia on rates of myringotomy [9] and hospitalizations for pneumonia [10]. In addition, the potential cost-effectiveness of $13 \mathrm{vPCV}$ and the 10 -valent vaccine (10vPCV) for Australian children compared to $7 \mathrm{vPCV}$ was estimated [11], and a retrospective economic evaluation of childhood 7vPCV in Australia was performed [11]. The objective of the current study is to quantify the clinical and economic impact of the universal PCV infant program since its introduction in Australia and to determine whether the program has shown good return on investment.

\section{METHODS}

\section{Model Structure}

A Microsoft Excel-based model was used to estimate the clinical and economic impact of the infant PCV program in Australia under a $3+0$ schedule. Details on the methodology have been previously published $[12,13]$. Briefly, to conduct the analysis, the number of cases of IPD, pneumonia and OM in all age groups as observed during the retrospective period using real-world data was estimated. The observed cases were compared to an estimated incidence of disease based on pre-PCV NIP incidence. Therefore, in Australia, the economic model estimates the number of pneumococcal disease cases from 2005 to 2017, inclusive. The model considers two scenarios: (1) the 'PCV scenario', in which the observed historical incidence from
2005 to 2017 represents the PCV NIP era in Australia, and (2) the 'no vaccine scenario,' a hypothetical scenario in which the number of disease cases is estimated assuming PCVs were never introduced into the NIP. For this hypothetical 'no vaccine' scenario, incidence data were based on observed incidences from 2001 to 2004 and assumed to be constant over the entire time period of the model (Fig. 1). Figure 1 shows only IPD incidence for those $<2$ years of age. The same approach was used for cases of IPD, pneumonia and OM for all age groups.

\section{Data}

\section{Epidemiologic Data}

Analyses were conducted for the entire Australian population stratified into seven age groups, $<2$ years, 2-4 years, 5-17 years, 18-34 years, 35-49 years, 50-64 years and $65+$ years, to observe the historical impact of infant vaccination in different age strata for vaccine age-eligible cohorts and in indirect age strata. For the observed data (vaccine) scenario, age-specific epidemiologic inputs were obtained for the incidence of IPD from the National Notifiable Diseases Surveillance System (NNDSS) Annual and Quarterly Reports (2005-2008) and the IPD Notifications dataset (2009-2017) (Table 1) [14]. IPD cases were assumed to be either pneumococcal meningitis or pneumococcal bacteremia to capture differences in costs, case fatality and sequelae (Table 2). The proportion of IPD that was meningitis was also derived from the NNDSS quarterly reports.

Data for all-cause pneumonia (hospitalized) and OM (hospitalized) were obtained from the Australian Institute of Health and Welfare (AIHW) Principal Diagnosis data cubes for separation statistics by principal diagnosis (2005-2017) [15]. General practitioner encounter data for non-hospitalized pneumonia and non-hospitalized OM encounters were obtained from Bettering the Evaluation and Care of Health (BEACH), a national randomly sampled survey of general practitioner activity [16].

Because several different health care interventions may have contributed to reductions in 


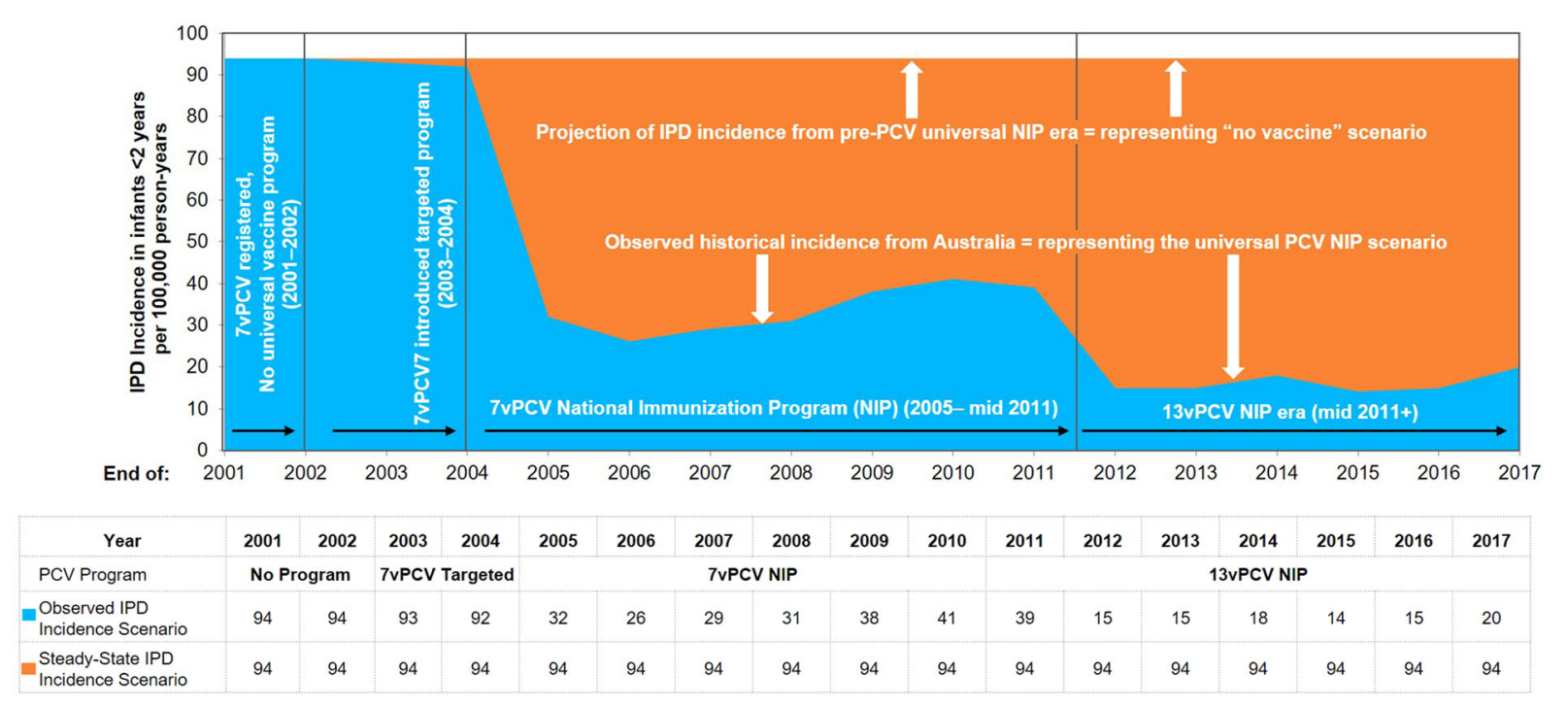

Fig. 1 Model structure and scenarios. IPD invasive pneumococcal disease, $P C V$ pneumococcal conjugate vaccine

pneumonia since the introduction of PCVs and to ensure we do not overestimate the historic impact of the vaccines, it was assumed in the base case that $20 \%$ of the observed reduction in all-cause pneumonia is attributable to PCVs. In the base case, it was assumed all reductions in OM were attributable to $7 \mathrm{vPCV}$ and $13 \mathrm{vPCV}$.

For the hypothetical no-vaccine scenario, incidence data as observed in the pre-7vPCV-era were used. For all outcomes this was based on the maximum incidence of the pre-vaccine era (2001-2004), the year in which 7vPCV was only available for a very small proportion of the total population in Australia and also the year when IPD became a notifiable disease in all Australian States and Territories [17]. The incidence values were then assumed to be constant over the time period of the analysis.

\section{Mortality}

For disease-related mortality risk, it was assumed that each case of pneumococcal bacteremia, pneumococcal meningitis or pneumonia (hospitalized or moderate/severe) is associated with a risk of mortality. Case fatality rates for pneumococcal disease reported by the NNDSS were used to estimate disease-related mortality risk.

\section{Disease Sequelae}

The percentages of meningitis patients that experienced moderate or severe sequelae were obtained from Newall et al., the proportion of infant meningitis cases resulting in lifelong sequelae (severe $=9.8 \%$; moderate $=14 \%$ ) [18]. Moderate sequelae were defined as mild hearing loss and severe sequelae as neurological impairment due to epilepsy, mental retardation and leg paresis. The authors had used the values reported by Bedford et al. [19].

\section{Utilities}

The population in each age group has a cumulative number of quality-adjusted life years based on each age band's age-specific baseline utility and the number of individuals in each group. Both short- and long-term utility decrements associated with cases of pneumococcal disease are then accounted for based on the number of cases of disease in each age group. All outcomes are associated with a disutility for the year in which a case of disease is experienced (Table 3), and sequelae are assumed to have a long-term disutility associated with each outcome. Specifically, moderate disability and severe disability carry a 0.09 and 0.54 lifetime disutility decrement, respectively (Melegaro and Edmunds 2004; [18]). 


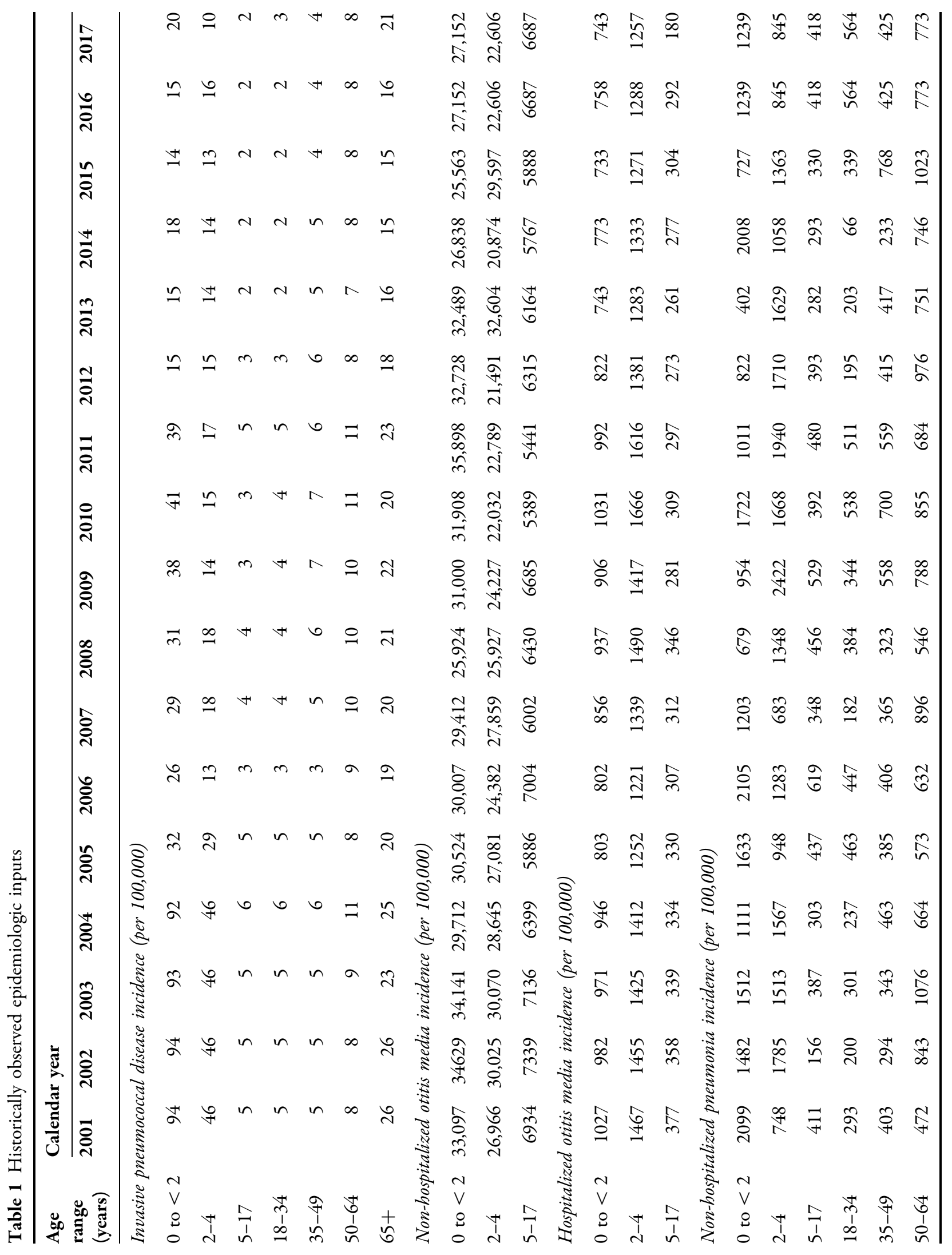




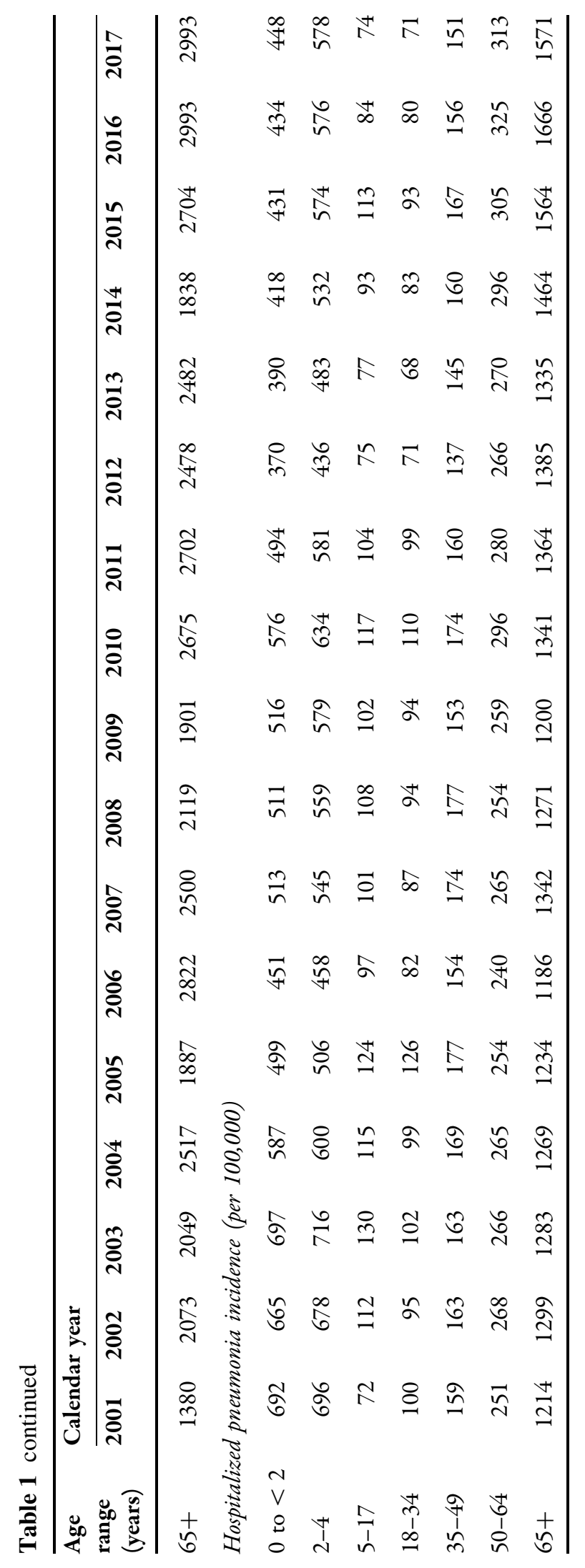


Table 2 Input parameters for age-specific population, costs and case fatality rates

\begin{tabular}{|c|c|c|c|c|c|c|c|}
\hline \multirow[t]{2}{*}{ Parameter } & \multicolumn{7}{|c|}{ Age range (years) } \\
\hline & $<2$ & $2-4$ & $5-17$ & $18-34$ & $35-49$ & $50-64$ & $\geq 65$ \\
\hline Population (2017) & 627,755 & 951,112 & $4,542,691$ & $5,401,119$ & $4,925,082$ & $4,363,428$ & $3,790,665$ \\
\hline $\begin{array}{l}\text { Percentage of IPD presenting as } \\
\text { meningitis }\end{array}$ & $13.0 \%$ & $6.0 \%$ & $11.0 \%$ & $3.0 \%$ & $4.0 \%$ & $8.0 \%$ & $7.0 \%$ \\
\hline \multicolumn{8}{|l|}{ Direct costs in Australian dollars } \\
\hline Bacteremia & $\$ 13,152$ & $\$ 13,152$ & $\$ 13,152$ & $\$ 13,152$ & $\$ 13,152$ & $\$ 13,152$ & $\$ 13,152$ \\
\hline Meningitis & $\$ 23,674$ & $\$ 23,674$ & $\$ 23,674$ & $\$ 23,674$ & $\$ 23,674$ & $\$ 23,674$ & $\$ 6,531$ \\
\hline Hospitalized pneumonia & $\$ 7,503$ & $\$ 7,503$ & $\$ 7,503$ & $\$ 7,503$ & $\$ 7,503$ & $\$ 7,503$ & $\$ 7,503$ \\
\hline Non-hospitalized pneumonia & $\$ 137$ & $\$ 137$ & $\$ 137$ & $\$ 137$ & $\$ 137$ & $\$ 137$ & $\$ 137$ \\
\hline Non-hospitalized otitis media & $\$ 73$ & $\$ 73$ & $\$ 73$ & & & & \\
\hline Hospitalized otitis media & $\$ 3154$ & $\$ 3154$ & $\$ 3154$ & & & & \\
\hline \multicolumn{8}{|l|}{ Case fatality rates } \\
\hline Bacteremia & $1.0 \%$ & $0.3 \%$ & $0.3 \%$ & $7.4 \%$ & $7.4 \%$ & $7.4 \%$ & $11.4 \%$ \\
\hline Meningitis & $2.0 \%$ & $0.3 \%$ & $0.3 \%$ & $7.4 \%$ & $7.4 \%$ & $7.4 \%$ & $11.4 \%$ \\
\hline Hospitalized pneumonia & $1.0 \%$ & $0.3 \%$ & $0.3 \%$ & $7.4 \%$ & $7.4 \%$ & $7.4 \%$ & $11.4 \%$ \\
\hline
\end{tabular}

$I P D$ invasive pneumococcal disease

\section{Economic Inputs}

Costs included vaccine acquisition and direct medical costs based on 2018 values reported in Australian dollars. Vaccine costs were taken from publicly available sources, reported as $\$ 81$ per dose, and assumed constant over the 13 -year period $[20,21]$. Vaccination rates in 1 -year-olds increased from $91 \%$ in 2005 to $94 \%$ in 2017 [22].

Hospitalization costs were obtained from the cost weights for AR-DRG version 8.0, Round 20 (2015-2016), adjusted to 2018 costs [23]. The cost of non-hospitalized otitis media and nonhospitalized pneumonia were obtained from Newall et al. [18] and Li et al. [11], respectively, both adjusted to 2018 costs (Table 2 ).

\section{Analysis}

\section{Base Case Analysis}

The number of cases for each scenario was estimated using the model, based on the annual incidence of each outcome (either observed or estimated in the no-vaccine era) adjusted based on the population in each age strata in each year. Averted cases and deaths were obtained by subtracting the observed historical cases in the vaccine scenario from the estimated cases in the "no-vaccine" scenario. To calculate quality-adjusted life years (QALYs) for both scenarios, individuals who did not experience a disease event had a baseline utility that was age specific, taken from a healthy population. If an individual experienced a disease event, a utility decrement was applied for each case of disease experienced annually. Direct costs associated with vaccine acquisition and management of pneumococcal disease cases were calculated for the PCV program scenario, whereas direct costs associated with management of disease only were calculated for the 'no vaccine' scenario.

The cumulative PCV program impact was estimated based on the resulting difference between pre-PCV NIP program incidence 
Table 3 Base case results: observed and estimated pneumococcal disease cases with and without a universal infant pneumococcal conjugate vaccine program, 2005-2017

\begin{tabular}{|c|c|c|c|}
\hline Parameter & $\begin{array}{l}\text { With infant PCV } \\
\text { Immunization program }\end{array}$ & $\begin{array}{l}\text { Without infant PCV } \\
\text { Immunization program }\end{array}$ & Incremental \\
\hline \multicolumn{4}{|l|}{ Outcomes } \\
\hline \multicolumn{4}{|l|}{ Cases of: } \\
\hline Bacteremia & 27,690 & 41,951 & $-14,261$ \\
\hline Meningitis & 4138 & 6269 & -2131 \\
\hline Non-hospitalized pneumonia & 403,721 & 666,693 & $-85,799$ \\
\hline Hospitalized pneumonia & 176,039 & 269,554 & $-16,260$ \\
\hline Non-hospitalized otitis media & $10,683,837$ & $12,259,328$ & $-1,575,491$ \\
\hline Hospitalized otitis media & 475,351 & 551,293 & $-75,942$ \\
\hline Deaths & 23,850 & 25,046 & -1195 \\
\hline Total life years & $358,103,104$ & $358,084,569$ & 18,535 \\
\hline Total QALYs & $303,508,288$ & $303,483,953$ & 24,335 \\
\hline \multicolumn{4}{|l|}{ Costs } \\
\hline Vaccine-related costs & $\$ 814,141,402$ & $\$ 0$ & $\$ 814,141,402$ \\
\hline IPD costs & $\$ 465,646,815$ & $\$ 710,358,982$ & $-\$ 244,712,167$ \\
\hline Pneumonia costs & $\$ 1,980,008,623$ & $\$ 2,113,761,080$ & $-\$ 133,752,457$ \\
\hline Otitis media costs & $\$ 2,277,040,418$ & $\$ 2,631,257,706$ & $-\$ 354,217,288$ \\
\hline Total costs & $\$ 5,536,837,258$ & $\$ 5,455,377,768$ & $\$ 81,459,490$ \\
\hline ICER & & & $\$ 3347$ \\
\hline
\end{tabular}

ICER incremental cost-effectiveness ratio, IPD invasive pneumococcal disease, $P C V$ pneumococcal conjugate vaccine, $Q A L Y$ quality-adjusted life year

carried forward and the observed incidence in the presence of a PCV NIP program. The costeffectiveness of the PCV program vs. 'no vaccine' scenario was calculated by dividing the incremental direct costs by the incremental QALYs gained over the cumulative retrospective time period. The time horizon covers the introduction of PCVs onto the NIP in 2005 up to 2017. The retrospective analysis did not consider discount rates, given that future returns are not calculated in this analysis. Discount rates were not used, as the past values were already realized.

\section{Sensitivity Analyses}

Owing to the uncertainty surrounding vaccine impact historically, several scenarios and sensitivity analyses were undertaken. First, as Australia had some level of uptake of $7 \mathrm{vPCV}$ in the years prior to 2005 when the universal infant NIP was introduced [24], two alternative scenarios were modeled which included earlier years of vaccination and changes in disease incidence, specifically starting the "vaccine" scenario in 2004 and 2003, respectively. Scenarios were tested to have uptake of $7 \mathrm{vPCV}$ of $5 \%$ in these years. Furthermore, including earlier years as part of the "vaccine" period changes the baseline comparison year for the "no 
vaccine" scenario, therefore including more historical data. Second, as other factors may have contributed to the decline in pneumonia and $\mathrm{OM}$ besides pneumococcal vaccination, several additional scenarios were undertaken varying the percent of $\mathrm{OM}$ and pneumonia that was assumed to have been reduced because of pneumococcal vaccination. Finally, given uncertainty in base case estimates, we varied these estimates by $\pm 20 \%$ for all direct costs, input parameters (disease and age groups), percentage of patients experiencing sequelae following cases of disease and utility decrements associated with disease cases/sequelae.

\section{RESULTS}

\section{Base Case Results}

Over the 13-year period of PCV use as part of the infant NIP in Australia, 7vPCV and 13vPCV (hereafter referred to as PCVs) were estimated to be administered to 3.35 million Australian infants between 2005 and 2017 in a $3+0$ schedule. Over this time, PCVs were estimated to have prevented approximately 1.77 million cases of pneumococcal disease and 1195 associated deaths across all ages because of both direct and indirect protection of the vaccine. These cases were made up of 16,392 cases of IPD, 102,059 cases of pneumococcal pneumonia and 1.65 million cases of OM (Table 3 ). This translates to approximately one case of pneumococcal disease averted for every two children vaccinated.

Inclusion of PCVs as part of the Australian infant NIP was estimated to cost approximately \$814 million AUD, which was offset by a reduction in direct medical costs of $\$ 733$ million AUD, resulting in a net cost to the Australian Health System of $\$ 81$ million AUD (Fig. 2). From reductions in costs and improvements in overall quality of life, the historic $7 \mathrm{vPCV}$ and $13 \mathrm{vPCV}$ programs are estimated to have cost \$3347 per QALY gained (Table 3).

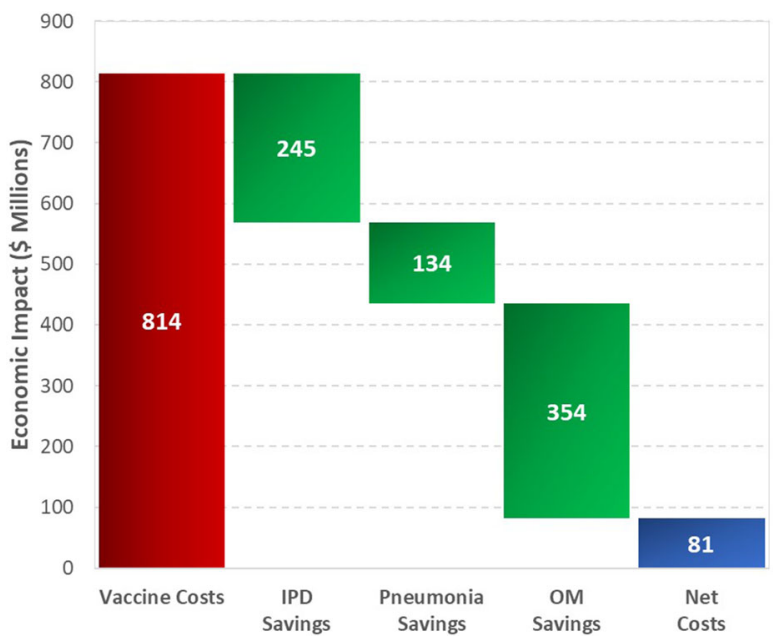

Fig. 2 Estimated historical economic impact of the pneumococcal conjugate vaccine program in Australia. IPD invasive pneumococcal disease, $O M$ otitis media

\section{Sensitivity Analyses}

Considering uncertainty in base case estimates, several sensitivity analyses were undertaken. First, when including 2004 and 2003, when PCVs were funded for children at high risk of IPD only, net vaccine costs increase to $\$ 817$ million AUD and $\$ 820$ million AUD respectively, during these years (Table 4). Similarly, the number of cases of disease prevented also increases to 1.83 million and 1.81 million cases of pneumococcal disease averted, respectively. These analyses result in ICERs slightly higher than the universal NIP analysis, at $\$ 4207$ per QALY and \$4901 per QALY including 2004 and 2003, respectively.

Sensitivity analyses were conducted on all direct cost input parameters (disease and age groups), percentage of patients experiencing sequelae following cases of disease and utility decrements associated with disease cases/sequelae (Table 4). These input parameters were varied by $\pm 20 \%$ of the base case estimates. Varying the direct cost input parameters resulted in ICER values ranging from $\$ 9369$ per QALY to 13vPCV dominating, for $-20 \%$ and $+20 \%$, respectively. As expected, reducing the utility decrement associated with disease cases/ sequelae by $20 \%$ caused less of a difference in the QALYs gained for with vs. without 
Table 4 Results of sensitivity analyses

\begin{tabular}{|c|c|c|c|c|c|c|}
\hline Scenario & $\begin{array}{l}\text { Total cases of } \\
\text { disease } \\
\text { averted }\end{array}$ & $\begin{array}{l}\text { Total } \\
\text { vaccine costs }\end{array}$ & $\begin{array}{l}\text { Total direct } \\
\text { medical costs } \\
\text { averted }\end{array}$ & Total costs & $\begin{array}{l}\text { Total } \\
\text { QALYs } \\
\text { gained }\end{array}$ & $\begin{array}{l}\text { ICER } \\
\text { (\$AUD/ } \\
\text { QALY) }\end{array}$ \\
\hline Base case & $1,769,884$ & $\$ 814,141,402$ & $\$ 732,681,912$ & $\$ 81,459,490$ & 24,335 & $\$ 3347$ \\
\hline $\begin{array}{l}\text { PCV introduction } \\
\text { assumed to be } 2004 \\
\text { ( } 5 \% \text { uptake) }\end{array}$ & $1,828,234$ & $\$ 817,168,010$ & $\$ 709,971,092$ & $\$ 107,196,917$ & 25,482 & $\$ 4207$ \\
\hline $\begin{array}{l}\text { PCV introduction } \\
\text { assumed to be } 2003 \\
\text { ( } 5 \% \text { uptake) }\end{array}$ & $1,810,775$ & $\$ 820,224,656$ & $\$ 692,035,644$ & $\$ 128,189,011$ & 26,158 & $\$ 4901$ \\
\hline $\begin{array}{l}\text { Direct costs by disease } \\
\text { and age group } \\
(+20 \%)\end{array}$ & $1,769,884$ & $\$ 814,141,402$ & $\$ 879,218,295$ & $\begin{array}{c}-\$ 65,076,893 \\
\text { (savings) }\end{array}$ & 24,335 & $\begin{array}{c}13 \mathrm{vPCV} \\
\text { cost } \\
\text { saving }\end{array}$ \\
\hline $\begin{array}{l}\text { Direct costs by disease } \\
\text { and age group } \\
(-20 \%)\end{array}$ & $1,769,884$ & $\$ 814,141,402$ & $\$ 586,145,530$ & $\$ 227,995,872$ & 24,335 & $\$ 9369$ \\
\hline $\begin{array}{l}\text { Disutilities for disease } \\
\text { cases and sequelae } \\
(+20 \%)\end{array}$ & $1,769,884$ & $\$ 814,141,402$ & $\$ 732,681,912$ & $\$ 81,459,490$ & 26,327 & $\$ 3094$ \\
\hline $\begin{array}{l}\text { Disutilities for disease } \\
\text { cases and sequelae } \\
(-20 \%)\end{array}$ & $1,769,884$ & $\$ 814,141,402$ & $\$ 732,681,912$ & $\$ 81,459,490$ & 22,344 & $\$ 3646$ \\
\hline
\end{tabular}

ICER incremental cost-effectiveness ratio, $P C V$ pneumococcal conjugate vaccine, $Q A L Y$ quality-adjusted life year

immunization (22,344 QALYs gained), resulting in a slightly larger ICER of $\$ 3646$ per QALY compared with the base case, $\$ 3347$ per QALY, whereas increasing the utility decrement associated with disease cases/sequelae by $20 \%$ resulted in more QALYs gained for with vs. without immunization $(26,327$ QALYs gained) and an ICER of \$3094 per QALY.

Moreover, we varied the proportions of $\mathrm{OM}$ and pneumonia that were assumed to have declined or changed due to PCV use in infants. In the base case, $20 \%$ of changes in pneumonia and $100 \%$ of changes in OM were assumed attributable to PCV use. Varying these parameters resulted in ICERs ranging from the scenario with PCV immunization being dominant (i.e., more effective and cost saving) to $\$ 37,611$ per QALY (Table 5).

\section{DISCUSSION}

The objective of this study was to determine whether the infant PCV program in Australia has been cost-effective compared with a "no vaccine" alternative since program inception. This retrospective modeling analysis showed the substantial public health and economic value that both the $7 \mathrm{vPCV}$ and $13 \mathrm{vPCV}$ programs have provided in Australia to date. Our result indicated that over a 13-year period, $7 \mathrm{vPCV}$ and 13vPCV have saved 1195 lives, prevented 1.77 million cases of pneumococcal disease and saved $\$ 733$ million AUD of direct health care costs. Correspondingly, the PCV program was shown to be cost-effective with an ICER of $\$ 3347$ per QALY gained. Maintaining $13 \mathrm{vPCV}$ in the Australian infant NIP is likely to 
Table 5 Sensitivity analyses on pneumonia and otitis media changes attributable to pneumococcal conjugate vaccines

\begin{tabular}{|c|c|c|c|c|}
\hline & \multicolumn{4}{|c|}{$\begin{array}{l}\text { ICERs with percent of otitis media declines } \\
\text { attributable to PCVs }\end{array}$} \\
\hline & & $100 \%$ & $50 \%$ & $25 \%$ \\
\hline \multirow[t]{3}{*}{ ICERs with percent of pneumonia changes attributable to PCVs } & $10 \%$ & $\$ 8622$ & $\$ 24,895$ & $\$ 37,611$ \\
\hline & $25 \%$ & $\$ 1722$ & $\$ 9471$ & $\$ 14,450$ \\
\hline & $50 \%$ & $13 \mathrm{vPCV}$ cost saving & $\$ 1400$ & $\$ 3712$ \\
\hline
\end{tabular}

$I C E R$ incremental cost-effectiveness ratio, $P C V$ pneumococcal conjugate vaccine

yield continued return on investment and provide sustained reductions in pneumococcal disease and pneumococcal-related deaths. This cost-effectiveness analysis is unique, given that real-world data are used to calculate the retrospective impact and return on investment observed from a direct health care perspective rather than assessing the cost-effectiveness of an infant vaccination program prospectively. For every two children vaccinated, approximately one case of pneumococcal disease has been averted in Australia.

The patient outcome results from this analysis are consistent with evaluations estimating the impact of PCV programs around the world [25]. In contrast, several studies have shown PCV programs provide a positive net return on investment and were evaluated as being cost saving [12, 13]. For example, in two studies in Mexico and Canada, PCV use was found to save $\$ 34$ billion MXM and $\$ 1.8$ billion CAD, respectively $[12,13]$. In this analysis, PCV13 was found highly cost-effective rather than cost saving. In contrast to the Canada and Mexico studies, the results in Australia may be considered conservative on the grounds that the majority of PCV use in Australia has been with a $3+0$ schedule, and Australia has only recently transitioned to a $2+1$ schedule in July 2018 . This decision and recommendation to implement a $2+1$ schedule originated from breakthrough cases of pneumococcal disease in children in the second year of life. In a study conducted by Jayasinghe et al. (2017) [26], reductions in vaccine-type IPD after the replacement of $7 \mathrm{vPCV}$ to $13 \mathrm{vPCV}$ were lower in Australia compared with high-income countries giving PCV booster doses. The newly implemented $2+1$ schedule could increase program effectiveness, especially in unvaccinated age groups, through more robust herd effects and therefore improve the cost-effectiveness of the program in the future. As shown in Table 1, substantial disease remains in the older populations (ages 50 + years), suggesting that Australian adults have yet to receive the full benefits from indirect protection through an infant vaccination program that includes a booster dose. Another difference between our current analysis versus the Mexico and Canada studies was the exclusion of indirect societal costs. Therefore, the public health impact of PCVs might be underestimated in this analysis and the full potential cost savings in Australia have yet to be realized.

There are several limitations in this retrospective analysis. First, the model did not consider the societal perspective, which encompasses a broader set of socioeconomic benefits in addition to health benefits. The Pharmaceutical Benefits Advisory Committee (PBAC) Guidelines recommend a health care system perspective to inform the base case [27]. However, recognition and inclusion of the broader societal value in economic evaluations is important to capture the true return on investment, considering vaccines generate substantial externalities (indirect benefits on third parties) that are not necessarily observed with other types of medical interventions [28]. Changes and improvements to the way vaccines are needed and assessments should include the value of benefits and costs to all parties involved $[29,30]$. By excluding and undercounting 
substantial portions of vaccines' full public health benefits, this analysis has undervalued the effect of the PCV infant program in Australia. For example, this study did not consider particular health benefits (i.e., amelioration of disease comorbidities, household health externalities, reductions in nosocomial infections, etc.) and non-health benefits (i.e., labor market productivity gains, nonmarket productivity and leisure gains, caregiver productivity gains, outbreak control cost savings, macroeconomic gains, equity gains, health system efficiency gains, political implications, etc.) [31]. The inclusion of the societal framework and the broader set of socioeconomic benefits would have resulted in larger returns on investment and broader public health effects that are consequences of PCV programs.

Second, several assumptions are made in the model and omission of long-term disease consequences due to data gaps. We did not include long-term consequences of IPD, pneumonia and OM given the lack of historical impact in Australia measuring these outcomes, which may underestimate the true clinical and economic impacts of PCV. Moreover, one model assumption was the percentage of changes in overall pneumonia and OM attributed to PCV use. PCVs have been shown to have an impact on all-cause $\mathrm{OM}$ and pneumonia; however, no robust data are available in Australia directly linking PCV use to these outcomes. Therefore, to ensure appropriate attribution of PCV use to these outcomes, it was assumed that $20 \%$ of the reduction of all-cause pneumonia cases was attributable to PCVs and all reductions in OM were attributable to PCVs in the base case. These assumptions were rigorously tested in sensitivity analyses, suggesting that under all scenarios, the PCV infant vaccination program remained cost-effective.

Finally, the adult 23vPPV program was implemented at the same time as the pediatric $7 \mathrm{vPCV}$ program, which may have caused the overestimation of the impact of the infant program on disease reduction in those $>$ 65 years of age. However, a significant burden of $13 \mathrm{vPCV}$ type pneumococcal disease persists in adults, regardless of herd effects observed from established pediatric PCV programs. This is observed in the retrospective data (Table 1). Recognizing the importance of adult vaccination and direct protection against pneumococcal disease in healthy adults, following a positive recommendation by the Pharmaceutical Benefits Advisory Committee, 13vPCV has been included on the NIP as a single dose for those aged $\geq 70$ years [32]. Directly protecting both infant and adult populations is needed to control vaccine-type pneumococcal disease and further reduce the overall burden of disease. Furthermore, if $13 \mathrm{vPCV}$ is replaced with a lower-valent PCV in the pediatric NIP or the adult NIP program becomes discontinued, reemergence of uncovered 13vPCV type disease is likely to occur in all age groups because of the removal of vaccine pressure, thereby reversing the substantial impact recognized to date. Replacing 13vPCV with a higher valent PCV in the adult and pediatric NIPs in Australia may help improve the impact and return on investment observed in this analysis. However, local epidemiology will need to be considered for choosing the option with the broadest coverage for the prevention on pneumococcal disease.

\section{CONCLUSION}

In conclusion, this study showed that since the introduction of PCVs in Australia, these vaccines have substantially reduced the clinical burden of pneumococcal disease and the unnecessary use of health care resources. Moreover, the analysis showed that PCVs have exceeded many expectations by preventing substantial disease burden and saving diseaserelated cost. Thus, PCVs should continue to be included in Australian NIPs in the future.

\section{ACKNOWLEDGEMENTS}

Funding. This study and the journal's rapid service fee was funded by Pfizer Inc.

Authorship. All named authors meet the International Committee of Medical Journal Editors (ICMJE) criteria for authorship for this 
article, take responsibility for the integrity of the work as a whole, and have given their approval for this version to be published.

Disclosures. Johnna Perdrizet and Matt Wasserman are employees of Pfizer Inc. Yuen S Lai, Scott Williams, and Valda a Struwig are employees of Pfizer Australia.

Compliance with Ethics Guidelines. BEACH data were purchased by the authors and did not require IRB/ethics approval. The other databases used are publicly available and are referenced within the manuscript.

Data Availability. All data generated or analyzed during this study are included in this published article/as supplementary information files.

Open Access. This article is licensed under a Creative Commons Attribution-NonCommercial 4.0 International License, which permits any non-commercial use, sharing, adaptation, distribution and reproduction in any medium or format, as long as you give appropriate credit to the original author(s) and the source, provide a link to the Creative Commons licence, and indicate if changes were made. The images or other third party material in this article are included in the article's Creative Commons licence, unless indicated otherwise in a credit line to the material. If material is not included in the article's Creative Commons licence and your intended use is not permitted by statutory regulation or exceeds the permitted use, you will need to obtain permission directly from the copyright holder. To view a copy of this licence, visit http://creativecommons.org/licenses/by$\mathrm{nc} / 4.0 /$.

\section{REFERENCES}

1. Australian Government, Department of Health. Australian Immunisation Handbook. Pneumococal Disease. 8 June 2018: https:// immunisationhandbook.health.gov.au/vaccinepreventable-diseases/pneumococcal-disease.
2. Huang SS, Johnson KM, Ray GT, Wroe P, Lieu TA, Moore MR, et al. Healthcare utilization and cost of pneumococcal disease in the United States. Vaccine. 2011;29(18):3398-412.

3. Le Meur JB, Ayukawa H, Proulx JF, De Wals P. Prevalence of middle ear abnormalities from otitis media in relation with pneumococcal vaccine use in the Inuit population of Nunavik, province of Quebec, Canada. Vaccine. 2018;36(34):5180-6.

4. Petit G, De Wals P, Law B, Tam T, Erickson LJ, Guay $\mathrm{M}$, et al. Epidemiological and economic burden of pneumococcal diseases in Canadian children. Can J Infect Dis. 2003.

5. Bettinger JA, Scheifele DW, Kellner JD, Halperin SA, Vaudry W, Law B, et al. The effect of routine vaccination on invasive pneumococcal infections in Canadian children, Immunization Monitoring Program, Active 2000-2007. Vaccine. 2010;28(9): 2130-6.

6. Pilishvili T, Lexau C, Farley MM, Hadler J, Harrison $\mathrm{LH}$, Bennett NM, et al. Sustained reductions in invasive pneumococcal disease in the era of conjugate vaccine. J Infect Dis. 2010;201(1):32-41.

7. Rudnick W, Liu Z, Shigayeva A, Low DE, Green K, Plevneshi A, et al. Pneumococcal vaccination programs and the burden of invasive pneumococcal disease in Ontario, Canada, 1995-2011. Vaccine. 2013;31(49):5863-71.

8. Bareja C, Toms C, Lodo K, de Kluyver R; Enhanced Invasive Pneumococcal Disease Surveillance Working Group. Invasive pneumococcal disease in Australia, 2009 and 2010. Commun Dis Intell Q Rep. 2015;39(2):E265-79.

9. Jardine A, Menzies RI, Deeks SL, Patel MS, McIntyre $\mathrm{PB}$. The impact of pneumococcal conjugate vaccine on rates of myringotomy with ventilation tube insertion in Australia. Paediatr Infect Dis J. 2009;28(9):1-5.

10. Jardine A, Menzies RI, McIntyre PB. Reduction in hospitalizations associated with the introduction of a pneumococcal conjugate vaccination schedule without a booster dose in Australia. Pediatr Infect Dis J. 2010;29(7):607-12.

11. Li A, Newall AT, Britt H, MacIntyre CR. The cost and disease burden of pneumonia in general practice in Australia. Vaccine. 2012;30:830-1.

12. Wasserman M, Palacios MG, Grajales AG, et al. Modeling the sustained use of the 13-valent pneumococcal conjugate vaccine compared to switching to the 10-valent vaccine in Mexico. Hum Vaccin Immunother. 2019;15(3):560-9. https://doi.org/10. $1080 / 21645515.2018 .1516491$. 
13. Wilson MR, Wasserman MD, Breton MC, Peloquin F, Earnshaw SR, McDade C, Sings HL, Farkouh RA. Health and economic impact of routine pediatric pneumococcal immunization programs in canada: a retrospective analysis. Infect Dis Ther. 2020;9(2): 341-53. https://doi.org/10.1007/s40121-02000294-6.

14. Australian Government, Department of Health. National Notifiable Diseases Surveillance System (NNDS). https://www1.health.gov.au/internet/ main/publishing.nsf/Content/cda-surveil-nndssnndssintro.htm.

15. Australian Institute of Health and Welfare (AIHW). Principal diagnosis data cubes. https://www.aihw. gov.au/reports/hospitals/principal-diagnosis-datacubes/contents/data-cubes. 2019.

16. BEACH. Family Medicine Research Centre: Bettering the Evaluation and Care of Health (BEACH). 2017. beach/.

17. Roche P, Krause V, Enhanced Pneumococcal Surveillance Group of the Pneumococcal Working Party of the Communicable Diseases Network Australia. Invasive pneumococcal disease in Australia, 2001. Communicable Diseases Intelligence Volume 26, No 4, December 2002.

18. Newall AT, Creighton P, Philp DJ, Wood JG, MacIntyre CR. The potential cost-effectiveness of infant pneumococcal vaccines in Australia. Vaccine. 2011;29:8077-85.

19. Bedford $\mathrm{H}$, de Louvois J, Halket S, Peckham C, Hurley R, Harvey D. Meningitis in infancy in England and Wales: follow up at age 5 years. BMJ. 2001;323:1-5.

20. Newall AT, Reyes JF, McIntyre P, Menzies R, Beutels $\mathrm{P}$ ad Wood JG. Retrospective economic evaluation of childhood 7-valent pneumococcal conjugate vaccination in Australia: uncertain herd impact on pneumonia critical. Vaccine. 2016;34:320-327.

21. Chen C, Wood JG, Beutels P, Menzies R, MacIntyre CR, Dirmesropian S, Reyes JF, McIntyre P, Newall AT. The role of timeliness in the cost-effectiveness of older adult vaccination: a case study of pneumococcal conjugate vaccine in Australia. Vaccine. 2018;36(10):1265-71. https://doi.org/10.1016/j. vaccine.2018.01.052 (Epub 2018 Feb 1).

22. Australian Government, Department of Health. Communicable Diseases Intelligence. Annual Immunisation Coverage Report (2006-2017). https://www1.health.gov.au/internet/main/ publishing.nsf/Content/cda-cdi-immunanrep.htm.
23. IHPA, in National Hospital Cost Data Collection, Public Hospitals Cost Report, Round 20 (Financial year 2015-16). 2018.

24. Roche P, Krause V, Cook H, Bartlett M, Coleman D, Davis C, Fielding J, Giele C, Gilmour R, Holland R, Kampen R, Enhanced Invasive Pneumococcal Diseases Surveillance Working Group. Invasive pneumococcal disease in Australia, 2005. Commun Dis Intell Q Rep. 2007;31(1):86-100.

25. Chapman R, Sutton K, Dillon-Murphy D, Patel S, Hilton B, Farkouh R, Wasserman M. Ten year public health impact of 13-valent pneumococcal conjugate vaccination in infants: a modelling analysis. Vaccine. 2020;38(45):7138-45. https://doi.org/10. 1016/j.vaccine.2020.08.068 (Epub 2020 Sep 8).

26. Jayasinghe S, Menzies R, Chiu C, Toms C, Blyth CC, Krause V, McIntyre P. Long-term impact of a " $3+0$ " schedule for 7- and 13-valent pneumococcal conjugate vaccines on invasive pneumococcal disease in Australia, 2002-2014. Clin Infect Dis. 2017;64(2):175-83.

27. Australian Government, Department of Health. Guidelines for preparing a submission to the Pharmaceutical Benefits Advisory Committee (PBAC Guidelines), version 5.0. https://pbac.pbs.gov.au/.

28. Bell E, Neri M, Steuten L. THE BRAVE INITIATIVE. The BRAVE narrative for broad recognition of value in vaccines engagement. OHE Research Paper, London: Office of Health Economics. 2020. https:// www.ohe.org/publications/brave-initiative-bravenarrative-broad-recognition-value-vaccinesengagement.

29. Bloom DE, Fan VY, Sevilla J. The broad socioeconomic benefits of vaccination. Sci Transl Med. $2018 ; 10(441)$.

30. Bloom DE, Brenzel L, Cadarette D, Sullivan J. Moving beyond traditional valuation of vaccination: needs and opportunities. Vaccine. 2017;35: A29-35. https://doi.org/10.1016/j.vaccine.2016.12. 001.

31. Bloom DE, Kirby PN, Pugh S, Stawasz A. Commentary: why has uptake of pneumococcal vaccines for children been so slow? The perils of undervaluation. Pediatr Infect Dis J. 2019.

32. Australian Government, Department of Health. National Centre for Immunisation Research and Surveillance. Pneumococcal vaccines for Australians. 1 July 2020 Fact sheet. URL: https://www. health.gov.au/health-topics/immunisation/ immunisation-services/pneumococcalimmunisation-service- 0 . 